\title{
Article \\ The Effect of Bismuth on Technological and Material Characteristics of Low-Alloyed Automotive Steels with a Good Machinability
}

\author{
Vladislav Kurka *, Zdeněk Kuboň (D), Ladislav Kander, Petr Jonšta (D) and Ondřej Kotásek
}

check for

updates

Citation: Kurka, V.; Kuboň, Z.; Kander, L.; Jonšta, P.; Kotásek, O. The Effect of Bismuth on Technological and Material Characteristics of Low-Alloyed Automotive Steels with a Good Machinability. Metals 2022, 12, 301. https://doi.org/10.3390/ met12020301

Academic Editors

Pasquale Cavaliere and Andrea Di Schino

Received: 20 December 2021

Accepted: 5 February 2022

Published: 9 February 2022

Publisher's Note: MDPI stays neutral with regard to jurisdictional claims in published maps and institutional affiliations.

Copyright: (C) 2022 by the authors. Licensee MDPI, Basel, Switzerland. This article is an open access article distributed under the terms and conditions of the Creative Commons Attribution (CC BY) license (https:// creativecommons.org/licenses/by/ $4.0 /$ )
MATERIAL AND METALLURGICAL RESEARCH Ltd., Pohraniční 693/31, 70300 Ostrava, Czech Republic; zdenek.kubon@mmvyzkum.cz (Z.K.); ladislav.kander@mmvyzkum.cz (L.K.); petr.jonsta@mmvyzkum.cz (P.J.); ondrej.kotasek@mmvyzkum.cz (O.K.)

* Correspondence: vladislav.kurka@mmvyzkum.cz

\begin{abstract}
The aim of this work is to compare the technological and material properties of $\mathrm{CMnCr}$ steels without bismuth, with 0.08 wt. \% Bi and 0.12 wt. \% Bi. Experimental heats showed that the most advantageous alloying of Bi into the heat was in the ladle, with an efficiency of about $20 \%$. The optimal temperature range for forming steel was found to be $1160-1050{ }^{\circ} \mathrm{C}$. With increasing $\mathrm{Bi}$ content, the formability of steels and plastic properties decreased, while the yield stress and tensile strength increased. Manganese sulfides, aluminum oxides, or oxysulfides, which were segregated both individually and in clusters, were found in the matrix of all tested steels. In steels with $\mathrm{Bi}$, the $\mathrm{Bi}$ particles segregate the separately in the form of globules, either as envelopes of elongated MnS or $\mathrm{Al}_{2} \mathrm{O}_{3}$ particles segregated in rows. Sulfur dot-shaped segregations in the steel with $0.12 \mathrm{wt} \%$ of $\mathrm{Bi}$ and the steel without Bi were essentially uniform over the whole area. For the steel with $0.08 \mathrm{wt} \%$ of $\mathrm{Bi}$, both dot-like and ray-ordered sulfur segregations were observed. The microstructure of all tested steels was ferritic-pearlitic with islands of bainite. Towards the center of the forged bars, variable shape and size of bainite blocks were observed. Machinability tests evaluated by the extend of tool wear showed that the most advantageous was $\mathrm{CMnCr}$ steel alloyed with 0.08 wt. \% Bi.
\end{abstract}

Keywords: low-alloyed automotive steel; bismuth; steelmaking; forging; microstructure; mechanical properties; machinability

\section{Introduction}

Free cutting steels belong to the group of special steels. The properties of free cutting steels are specifically designed for the easy machining of products, which is one of the key technological requirements, especially in the automotive industry. Machining costs represent approximately $50 \%$ of the value of the machined part. Other properties, such as response to heat treatment, mechanical resistance, fatigue characteristics, corrosion resistance, brittle fracture properties, etc., are secondary aspects of these steels, although in many cases they can be a determining parameter for the selection of steel grade [1].

From an industrial point of view, a free cutting steel is one that contains more sulfur than carbon. Thanks to the higher content of sulfur or phosphorus, these steels are easy to machine. Alloying with sulfur and lead is used in the development and optimization of the properties of free cutting steels, but also the addition of other elements like phosphorus, lead, selenium, tellurium, antimony, calcium, bismuth, or tin [2].

Free cutting steels produce small, dud, easily breaking, brittle chips during machining, which increases the machinability of the material by reducing the length of contact between the workpiece and cutting tool, thus reducing friction, the heating of the tool and workpiece, and tool wear, while increasing performance. According to [3], free cutting steels can be divided into four main types. These are steels with an increased content of sulfur, phosphorus and sulfur, lead, or super (alloyed with selenium, tellurium and bismuth). 
From the machinability point of view, the key criteria are cutting force, smoothness of the machined surface, chip shape, tool life, and possibly also the coefficient of friction and cutting temperature [4-7].

In addition to optimizing the machining process itself, higher machinability can also be achieved in the steel stage of steel production, namely:

- $\quad$ By adding non-metallic and metallic soluble elements, e.g., Mn, S, Se.

- By adding metallic and non-metallic insoluble elements such as $\mathrm{Pb}, \mathrm{Bi}, \mathrm{Te}$.

- By reducing the amount of hard particles that lead to a reduction in the abrasiveness of the steel during machining; something which, however, requires the optimization of steel production technology.

It is generally believed that the metallurgical processing of steels can improve their machinability due to LME (Liquid Metal Embrittlement), reducing BUE (Built-Up Edgeplastically deformed particles of the material being machined) on the blade, and forming a reinforced layer on the machined surface [8].

Sulfur together with manganese forms MnS inclusions in free cutting steels [9]. It is generally stated that MnS inclusions result in chip breaking discontinuities in the microstructure. MnS inclusions form a large amount of soft particles that are available for the formation of microscopic crack nuclei, which increases machinability [10], while inclusions formed by hard and abrasive oxides have a negative effect where machining is concerned [11]. MnS also acts as a lubricant at the tool-chip interface, and at the same time creates a protective coating for the tool. The result of this process is a reduction in cutting force and temperature and a significant reduction in tool wear. The wear rate of the tool decreases with increased volume fraction of MnS inclusions [8,12]. Kato et al. [13] have experimentally shown that the morphology and distribution of MnS inclusions have an effect on machinability, on cold wear, and on contact fatigue. In terms of the better machinability of the material, the presence of a smaller number of large inclusions in the matrix is more advantageous than a large number of small inclusions [14]. Several innovative methods for managing and controlling the morphology of MnS inclusions have been patented $[5,15,16]$.

Lead, which is added to some free cutting steels, acts here as an internal lubricant. To improve machinability, contents in the range of $0.15-0.35 \mathrm{wt}$. \% have generally been reported [1,16,17]. Alloying molten steel with lead is nevertheless difficult because lead has a low melting point and a boiling point of about $1700{ }^{\circ} \mathrm{C}$ or $1500{ }^{\circ} \mathrm{C}$ in the form of oxide. Lead is a heavy metal with a higher density than steel, which means that during conventional steelmaking processes, lead settles to the bottom of the melting bath or it evaporates and releases toxic fumes. Due to the almost zero solubility of lead in steel at room temperature, lead in steel forms inclusions, either alone or in junction with MnS [6].

At present, however, manufacturers are forced to develop lead-free free cutting steels. This is due to the tightening of standards that limit the amount of lead and other heavy metals in water, food, and the environment. Most heavy metals, including lead, are harmful in very small quantities. Health risks, as well as growing environmental pressures to remove lead and its alloys from the environment, have led to efforts to find lead-free alternatives for free cutting steel. One possibility is the development of free cutting steels with bismuth, which has a similar effect as lead on machinability [18].

Bismuth alloying generally leads to a grain refinement, reducing the proportion of carbide phase and also homogenizing the steel structure. Due to grain refinement, the yield strength and tensile strength increase with increasing Bi content. In steels, Bi precipitates either alone in globular form, or in the form of oxides and sulfides. Bismuth, similar to sulfur, segregates at grain boundaries and reduces their cohesive strength, and therefore also has a negative effect on formability [19].

In the solid state, bismuth is insoluble in steel and is present in the form of microscopic particles with a low melting point of only $271^{\circ} \mathrm{C}$, which significantly impairs the mechanical and corrosion properties of steel. Since the boiling point of bismuth $\left(1560{ }^{\circ} \mathrm{C}\right)$ [20] is very close to the casting temperature of steel, there is a problem with its volatility and evaporation during casting. It has a lower density than lead, and therefore its tendency to 
segregate is lower. The positive effect of bismuth on machinability can be achieved when its content is approximately three times lower than that of lead. Bismuth is, however, about nine times more expensive than lead, and the very low number of its suppliers can be a problem. In general, the effect of bismuth on machinability includes:

- The formation of a lubricating film due to the low melting point of bismuth;

- Its functioning as a diffusion barrier;

- Deposits on MnS particles and a reduction in their ductility;

- $\quad$ Stress concentration and the formation of cavities and microcracks; and

- Embrittlement of steel and cracking in the temperature range of $300-400{ }^{\circ} \mathrm{C}$.

Liu et al. [21,22] analyzed the effect of bismuth on the shape of inclusions and the formability of free cutting steels. Mostly three types of inclusions have been found, namely isolated MnS inclusions, isolated Bi inclusions, and MnS inclusions surrounded by a Bi envelope $(\mathrm{MnS}+\mathrm{Bi})$. The higher the content of bismuth in steel, the worse its formability in the temperature range of $850-1100{ }^{\circ} \mathrm{C}$. This is due to the segregation of bismuth at the grain boundaries in liquid form and in the form of low-melting particles, as well as to the presence of a ferritic film and non-recrystallized austenite at the grain boundaries. To eliminate the harmful effect of Bi on the hot ductility of steel, a low deformation rate during the hot forming of free cutting steels with bismuth is recommended [23,24].

$\mathrm{Hu}$ et al. [14] studied the effect of different contents of bismuth $(0.021 \mathrm{wt}$ \%, $0.054 \mathrm{wt}$. \%, 0.071 wt. \%) on the microcleanliness of SAE 1215 free cutting steel. As the content of Bi increases, the size of sulfides decreases, and at the same time, a change in their morphology was observed, from longitudinal to oval or spherical inclusions of sulfide.

It is generally believed that bismuth is definitely one of the elements that have great potential to replace lead in free cutting steels [25-27].

The aim of the paper is to present the effect of bismuth on the technological and material characteristics of low-alloyed automotive steels with good machinability.

The research and development in this field of expertise was motivated by the effort to increase the competitiveness of industry partners in the market with high quality automotive steels.

\section{Materials and Methods}

Experiments were realized in three trial heats of low-alloy $\mathrm{CMnCr}$ steels, which were alloyed with bismuth in the form of a filled profile with a composition of $93 \mathrm{wt}$. \% Bi and 7 wt. $\% \mathrm{CaCO}_{3}$. Heats were gradually produced in the atmospheric induction furnace (AIF) made by INDUCTOTHERM EUROPE LTD, Worcestershire, England. The first heat was not alloyed with bismuth, the final bismuth content for the second and third heat was targeted at $0.08 \mathrm{wt}$. \% and $0.12 \mathrm{wt}$. \%. Verification of the effect of bismuth on the technological and material characteristics of steels was performed on the ingots and forged bars.

Six circular ingots (two from each trial heat), each weighing $150 \mathrm{~kg}$, were bottom poured. Ingots had a diameter of $180 \mathrm{~mm}$ and a length of $700 \mathrm{~mm}$.

To assess the hot deformation behavior of the steels, physical simulations of metal forming were performed using a universal torsion plastometer (Setaram, Caluire-et-Cuire, France). Specimens with a diameter of $10 \mathrm{~mm}$ and a length of $200 \mathrm{~mm}$ sampled from experimental ingots were used. The tests were carried out in the temperature range 850-1200 ${ }^{\circ} \mathrm{C}$, in $50^{\circ} \mathrm{C}$ steps. Four different strain rates were used, namely $0.02 \mathrm{~s}^{-1}, 0.09 \mathrm{~s}^{-1}$, $0.42 \mathrm{~s}^{-1}, 1.94 \mathrm{~s}^{-1}$. Formability was expressed by fracture strain intensity $\mathrm{Se}_{f}$ according to Equitation (1).

$$
S e_{f}=\frac{2}{\sqrt{3}} \cdot \operatorname{argsinh} \frac{2 \cdot \pi \cdot R \cdot N}{3 L}
$$

where $N$ is number of specimen revs to fracture [-], $R$ radius of the specimen [mm], $L$ is initial gauge length of specimen [mm]. 
Based on the formability test results, ingots were forged with a hydraulic press into billets with a square cross section with a side length of $80 \mathrm{~mm}$, and then the billets were heated and forged with a power hammer into bars with a diameter of $58 \mathrm{~mm}$. After forging, the bars were cooled in air and subsequently were rough-machined into bars with a diameter of $50 \mathrm{~mm}$.

Chemical composition of samples was verified by optical emission spectrometry on a stationary SPECTROMAX analyzer (SPECTRO Analytical Instruments, GmbH, Kleve, Germany); carbon and sulfur were determined by combustion method on a stationary element analyzer Eltra CS2000 (ELTRA, GmbH, Haan, Germany).

Baumann prints for macrostructural evaluation was performed in accordance with ISO 4968 by sulphuric acid solution. The initial semi-finished products were rough-machined bars with a $50 \mathrm{~mm}$ of diameter. The content of nonmetallic inclusions was determined according to SEP 1572 at $100 \times$ magnification. Structural analyses were performed after etching samples in a solution of $4 \% \mathrm{HNO}_{3}$ in ethyl alcohol. GX51 light microscope (OLYMPUS, Co., Tokyo, Japan) was used for microscopic observations. Electron microscopy analyses were performed using a JSM5510 scanning electron microscope (JEOL Co., Tokyo, Japan) equipped with an X-max 20 energy dispersion spectrum analyzer (Oxford Instruments, Inc., Abingdon, UK).

The mechanical properties of the bars were verified by a tensile test using a $100 \mathrm{kN}$ universal testing machine (walter + bai ag, Löhningen, Switzerland), by Charpy-V impact test on a Charpy PH300 (walter + bai ag, Löhningen, Switzerland) and by Brinell Hardness test HBW 187.5/2.5 using an Emco M1C 010 hardness tester (EMCOTEST, GmbH, Kuchel, Austria). The test specimens for the tensile test had a diameter of $10 \mathrm{~mm}$ and an initial gauge length of $50 \mathrm{~mm}$. Standard test specimens with a V-notch with a depth of $2 \mathrm{~mm}$ were used for the Charpy impact test. Hardness was measured on the ends of Charpy specimens. All tests were always performed at ambient temperature.

The machinability was evaluated on the UT-300L CNC lathe machine (ACCUWAY MACHINERY Co., Ltd., Shengang, Taiwan). A CVD-coated turning insert (grade T9115) was used for the machining test. The cutting conditions corresponded to common machining conditions in the automotive industry and were set as follows: circumferential speed $200 \mathrm{~m} \cdot \mathrm{min}^{-1}$, material removal depth $1.5 \mathrm{~mm}$, tool displacement per rotation $0.2 \mathrm{~mm} \cdot \mathrm{rev}^{-1}$; no cooling was used.

The initial semi-finished products were rough-machined bars with a diameter of $50 \mathrm{~mm}$, which were turned until they were $20 \mathrm{~mm}$ in diameter and $100 \mathrm{~mm}$ long. Turning was only longitudinal in order to load the edge of the blade on the one side. A total of five bars were turned, for a total length of machined material of $500 \mathrm{~mm}$.

\section{Results and Discussion}

\subsection{Experimental Ingot Production}

Three experimental heats with different bismuth content were produced in the same way. The CMnCr steel melt was cast from AIF into a ladle at $1680^{\circ} \mathrm{C}$. Bismuth was added into the steel in a ladle at $1575{ }^{\circ} \mathrm{C}$. The efficiency of alloying with bismuth varied for individual heats and ranged from 9.8 to $15.2 \mathrm{wt}$. \%. When alloying bismuth into the heat inside the ladle, its usability was five times higher compared to alloying directly in the AIF crucible, and vaporization of bismuth was very easy. This fact is related to the small depth of the melt in the AIF crucible, which the authors have verified experimentally in the past. The use of bismuth was only $3.3 \mathrm{wt}$. \% in this case.

The chemical composition of the individual heats is given in Table 1 . The first heat did not contain bismuth, and the second and third heats were alloyed with $0.08 \mathrm{wt}$. \% or 0.12 wt. \%. 
Table 1. Chemical composition of the CMnCr steels [wt. \%].

\begin{tabular}{cccccccccccc}
\hline Heat No. & $\mathbf{C}$ & $\mathbf{M n}$ & $\mathbf{S i}$ & $\mathbf{A l}$ & $\mathbf{S}$ & $\mathbf{C u}$ & $\mathbf{N i}$ & $\mathbf{C r}$ & $\mathbf{B i}$ & $\mathbf{M n} / \mathbf{S}$ \\
\hline 1 & 0.19 & 1.49 & 0.05 & 0.076 & 0.024 & 0.05 & 0.08 & 1.16 & - & 62.1 \\
\hline 2 & 0.19 & 1.37 & 0.07 & 0.082 & 0.022 & 0.05 & 0.07 & 1.14 & 0.08 & 62.3 \\
\hline 3 & 0.21 & 1.28 & 0.05 & 0.056 & 0.021 & 0.07 & 0.07 & 1.21 & 0.12 & 61.0 \\
\hline
\end{tabular}

\subsection{Formability}

Formability was expressed as the temperature dependence of the fracture strain intensity of the tested material. Bismuth-free $\mathrm{CMnCr}$ steel was difficult to form. The formability of steels further decreased with the increasing content of bismuth in the steel, i.e., with a bismuth content of 0.08 wt. $\%$ by $25 \%$, and 0.12 wt. $\%$ by $40 \%$ compared to $\mathrm{CMnCr}$ steel without bismuth. The results are summarized in Figures 1-3, which show that the formability of the steels increases with degreasing forming temperature and an increasing strain rate.

Based on the results of formability tests, a forming temperature range of $1160-1050{ }^{\circ} \mathrm{C}$ and strain rate of $1.94 \mathrm{~s}^{-1}$ were established for forging of the bars.

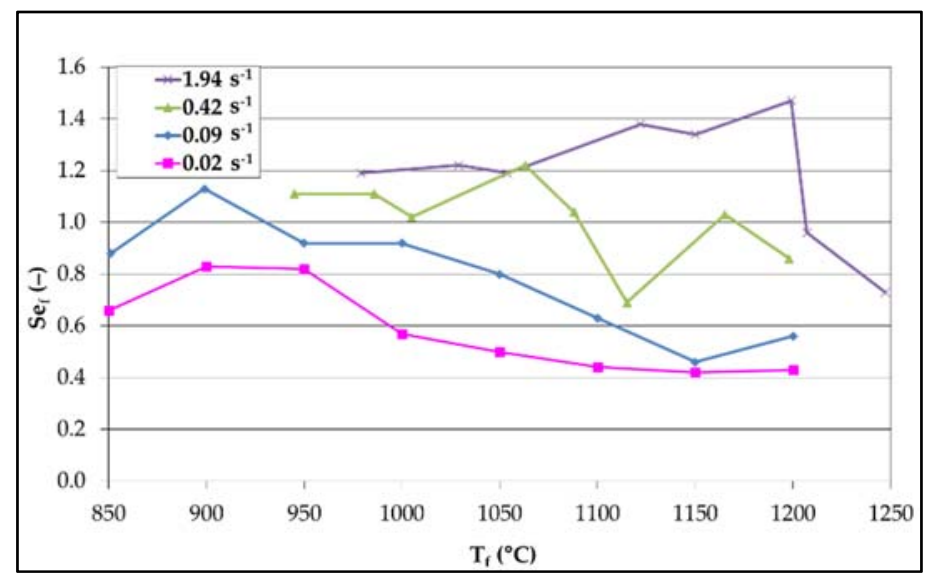

Figure 1. Dependence of the fracture strain intensity $\left(S e_{f}\right)$ on the test temperature $\left(T_{f}\right)$, and strain rate, Bi-free steel.

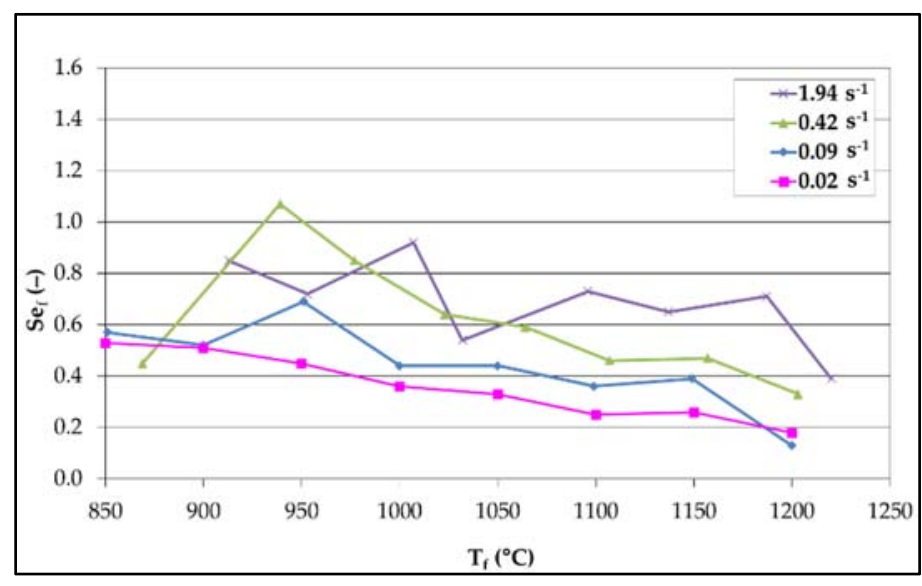

Figure 2. Dependence of the fracture strain intensity $\left(S e_{f}\right)$ on the test temperature $\left(T_{f}\right)$, and strain rate, 0.08 wt. $\%$ Bi. 


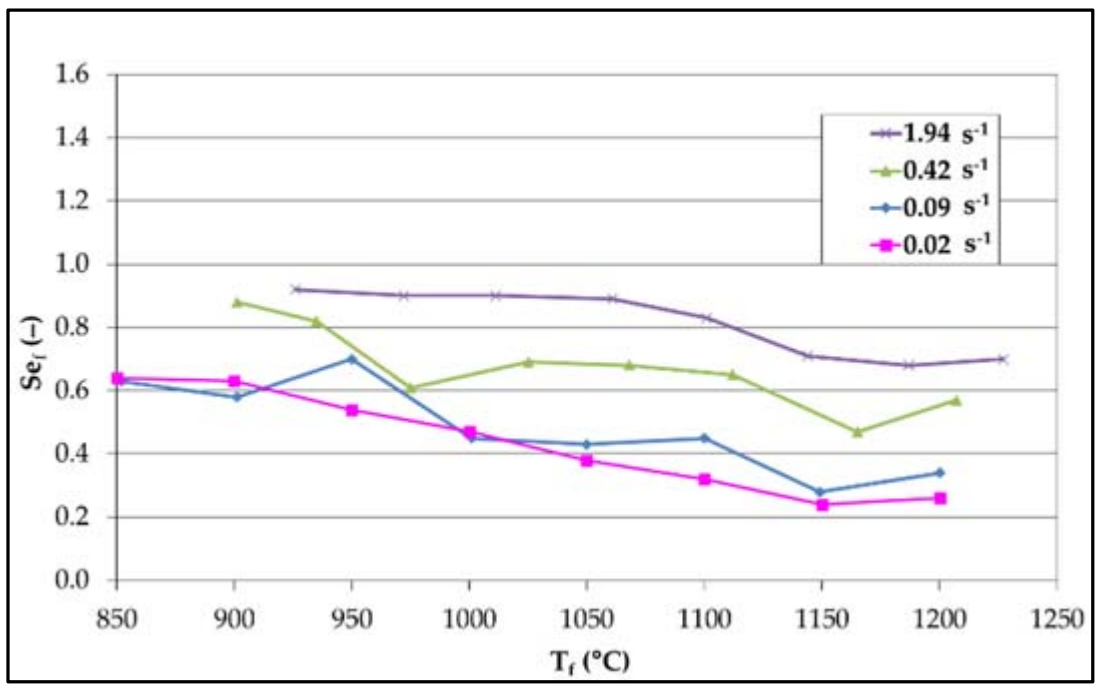

Figure 3. Dependence of the fracture strain intensity $\left(S e_{f}\right)$ on the test temperature $\left(T_{f}\right)$, and strain rate, 0.12 wt. $\%$ Bi.

\subsection{Mechanical Properties}

The results of the mechanical tests are summarized in Table 2. It is evident that an increasing content of bismuth increases yield stress and tensile strength while decreasing ductility and contraction. The optimal combination of strength and stress, plastic properties and toughness was achieved for $\mathrm{CMnCr}$ steel with $0.08 \mathrm{wt}$. \% Bi.

Table 2. Mechanical properties of CMnCr steels.

\begin{tabular}{ccccccc}
\hline \multirow{2}{*}{ CMnCr Steel } & $\begin{array}{c}\text { Tensile } \\
\text { Strength }\end{array}$ & Yield Stress & Elongation & $\begin{array}{c}\text { Reduction } \\
\text { of Area }\end{array}$ & $\begin{array}{c}\text { Absorbed } \\
\text { Energy }\end{array}$ & $\begin{array}{c}\text { HBW } \\
\mathbf{1 8 7 . 5 / 2 . 5}\end{array}$ \\
\cline { 2 - 7 } & {$[\mathrm{MPa}]$} & {$[\mathrm{MPa}]$} & {$[\%]$} & {$[\%]$} & {$[\mathrm{J}]$} & \\
\hline Bi-free & 684 & 429 & 15 & 42 & 30 & 222 \\
\hline 0.08 wt. \% Bi & 592 & 343 & 20 & 47 & 74 & 178 \\
\hline 0.12 wt. \% Bi & 722 & 480 & 13 & 37 & 18 & 247 \\
\hline
\end{tabular}

\subsection{Machinability Tests}

The machinability of the steel was evaluated on the basis of tool wear after $30 \mathrm{~min}$ of machining, chip shape, and surface roughness.

For bismuth-free $\mathrm{CMnCr}$ steel, a higher temperature in the cutting area was reached, which resulted in build-up on the edge of the tool, see Figure 4a. A higher degree of wear of the tool edge was also observed. The chip formation was very similar to Bi alloy steels, but their " $\mathrm{C}$ " shape was more open, and the chip broke further from the flank of the tool, see Figure $5 \mathrm{a}$.

$\mathrm{CMnCr}$ steel with $0.08 \% \mathrm{Bi}$ appeared to be the most suitable due to the slight wear of the tool, see Figure $4 b$. The chips were satisfactory in shape and size, see Figure $5 b$.

The tool wear for $\mathrm{CMnCr}$ steel with $0.12 \% \mathrm{Bi}$ was lower than for steel without $\mathrm{Bi}$, see Figure $4 \mathrm{c}$. The chip formation and shape were optimal, see Figure $5 \mathrm{c}$. The chips were tiny and easily removed from the cut when breaking them away from the tip. A longer spiral chip was formed as the tip of the workpiece (bar) was reached, but removal from the cutting point was also good without affecting the already machined surface. 


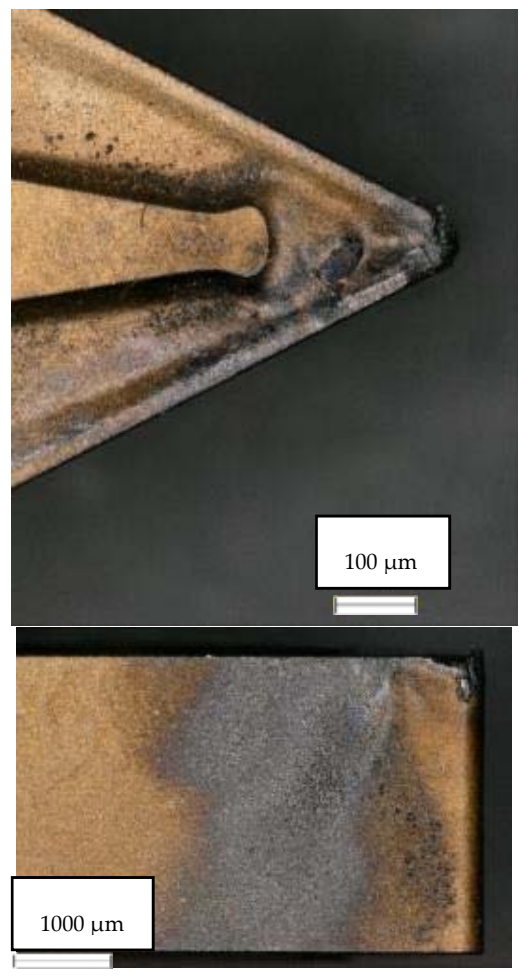

(a)

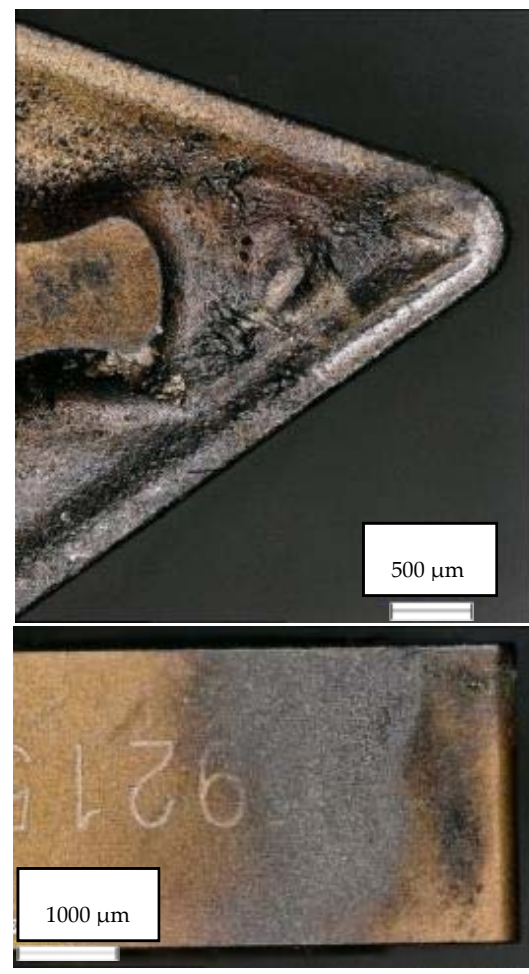

(b)

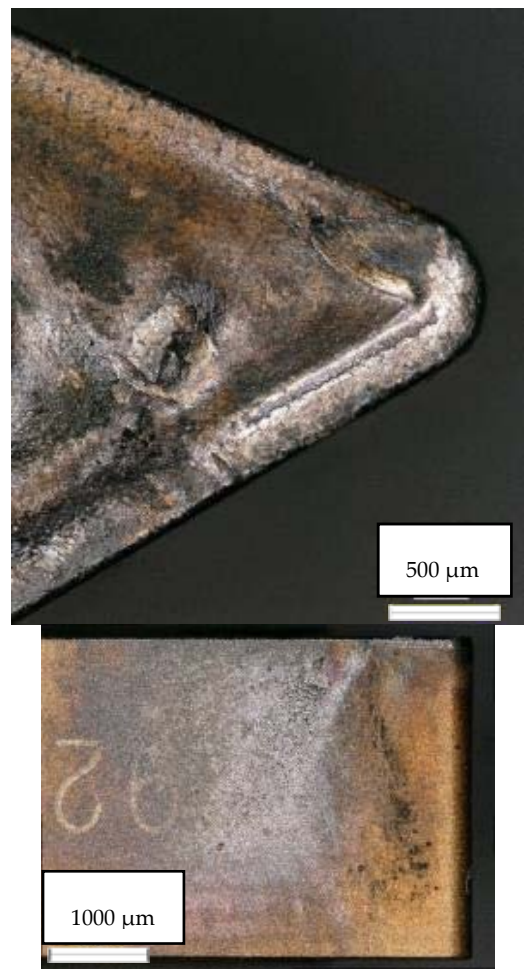

(c)

Figure 4. Wear of inserts after $30 \mathrm{~min}$ of machining a $\mathrm{CMnCr}$ steel bar: (a) Bi-free, wear of the insert unsatisfactory; (b) $0.08 \% \mathrm{Bi}$, wear of the insert satisfactory; (c) $0.12 \% \mathrm{Bi}$, wear of the insert satisfactory.

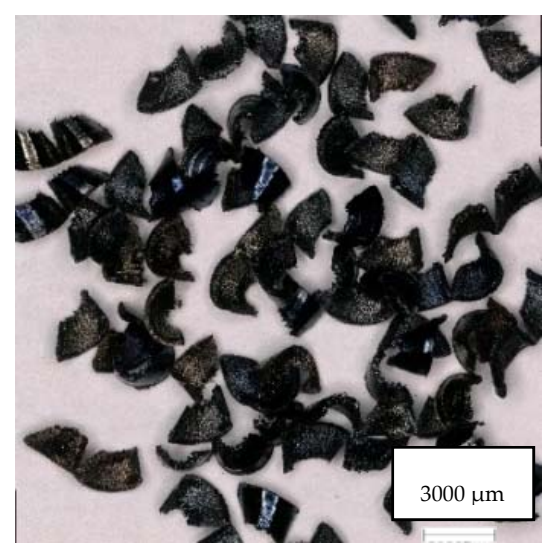

(a)

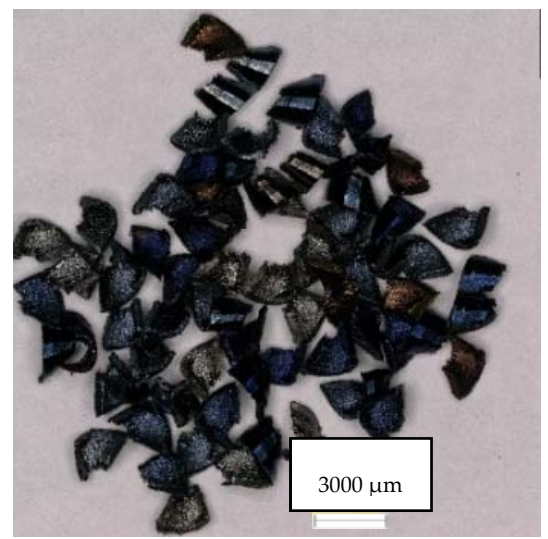

(b)

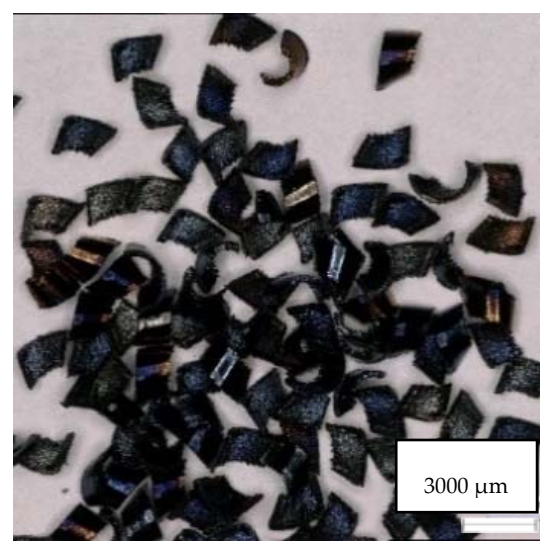

(c)

Figure 5. Chips after $30 \mathrm{~min}$ of machining of $\mathrm{CMnCr}$ steel ingots: (a) Bi-free, chips are satisfactory; (b) $0.08 \% \mathrm{Bi}$, chips are satisfactory; (c) $0.12 \% \mathrm{Bi}$, chips are satisfactory.

The surface roughness of the machined bars was monitored during the machinability tests, see Figure 6. The best surface roughness was observed for steel with $0.12 \mathrm{wt}$. \% Bi. Steel with $0.12 \mathrm{wt}$. \% Bi had the best surface roughness, see Figure 6, because it possessed the highest hardness, $247 \mathrm{HBW}$, and the lowest absorbed energy, $18 \mathrm{~J}$, see Table 2. 


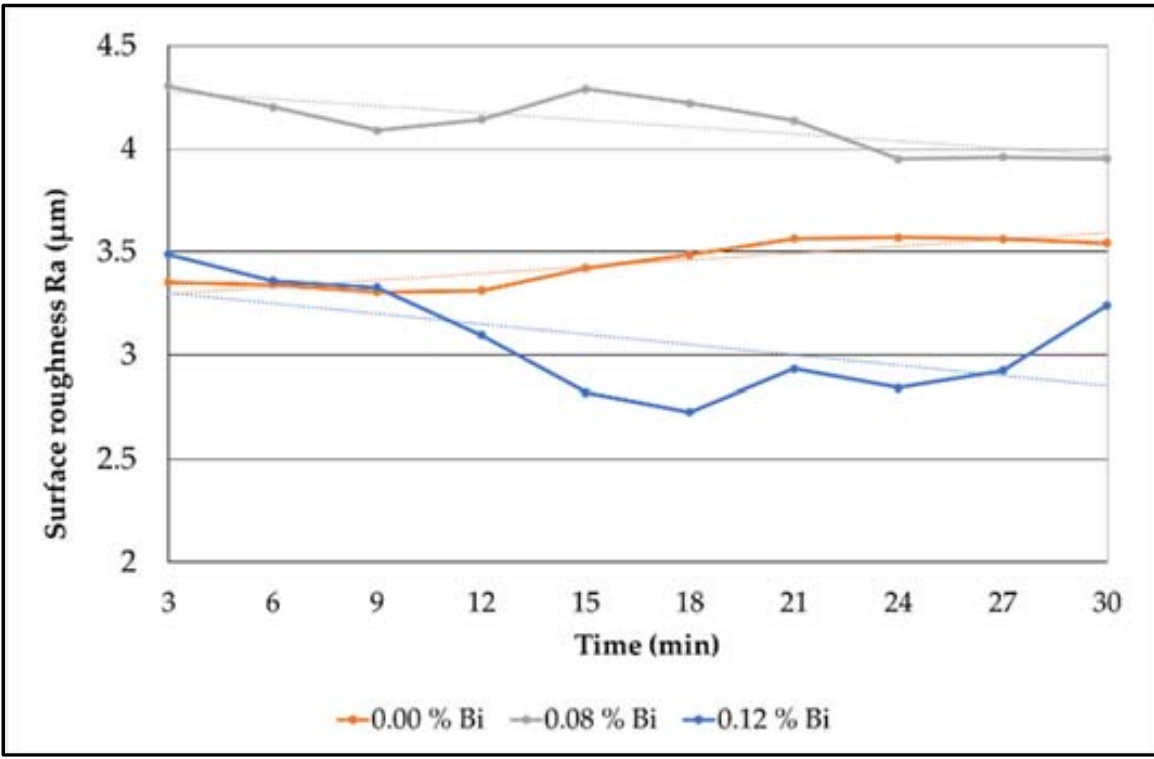

Figure 6. Dependence of the surface roughness of the material over time during the machinability tests of $\mathrm{CMnCr}$ steels with different Bi contents.

\subsection{Structural Analysis, Microcleanliness, X-ray Microanalysis}

Distribution of sulfur inclusions in a cross-section of the steel bars evaluated by Baumann print showed that in the steel with $0.12 \mathrm{wt}$. \% of Bi and the steel without Bi, dot-shaped sulfur segregations were essentially uniformly distributed over the whole area; Figure $7 \mathrm{a}, \mathrm{c}$. For the steel with 0.08 wt. \% of Bi, both dot-like and ray-ordered sulfur segregations were observed, see Figure $7 \mathrm{~b}$.

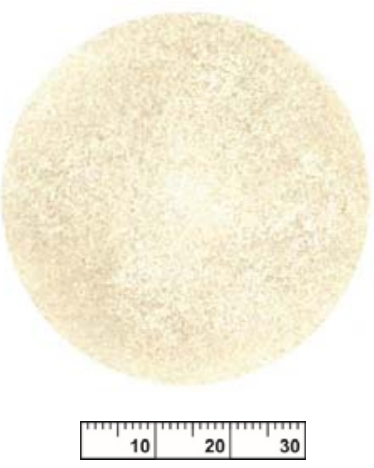

(a)

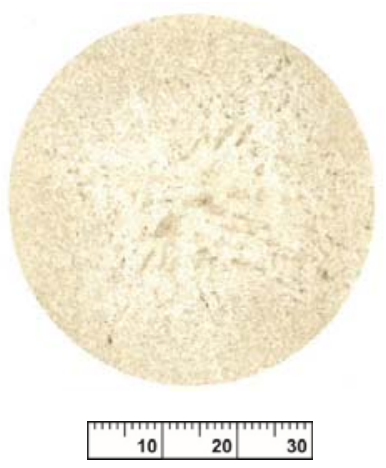

(b)

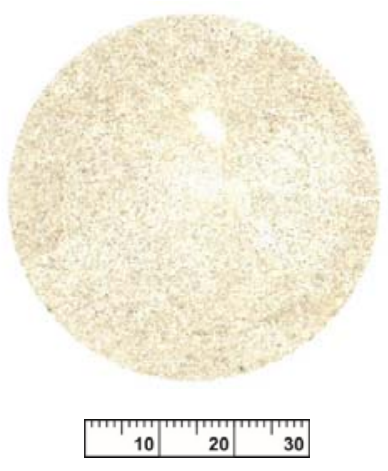

(c)

Figure 7. Results of Baumann print of the $\mathrm{CMnCr}$ steel: (a) without $\mathrm{Bi}$, (b) with $0.08 \mathrm{wt} . \% \mathrm{Bi}$, (c) with 0.12 wt. \% Bi.

Microcleanliness analyses showed that the amount sulfur inclusions and their uneven distribution in steel matrix was similar for all test samples (evaluation number was 1.1 according to SEP 1572). Relatively small, spherical, or slightly elongated sulfidic inclusions were observed, see Figure 8. 


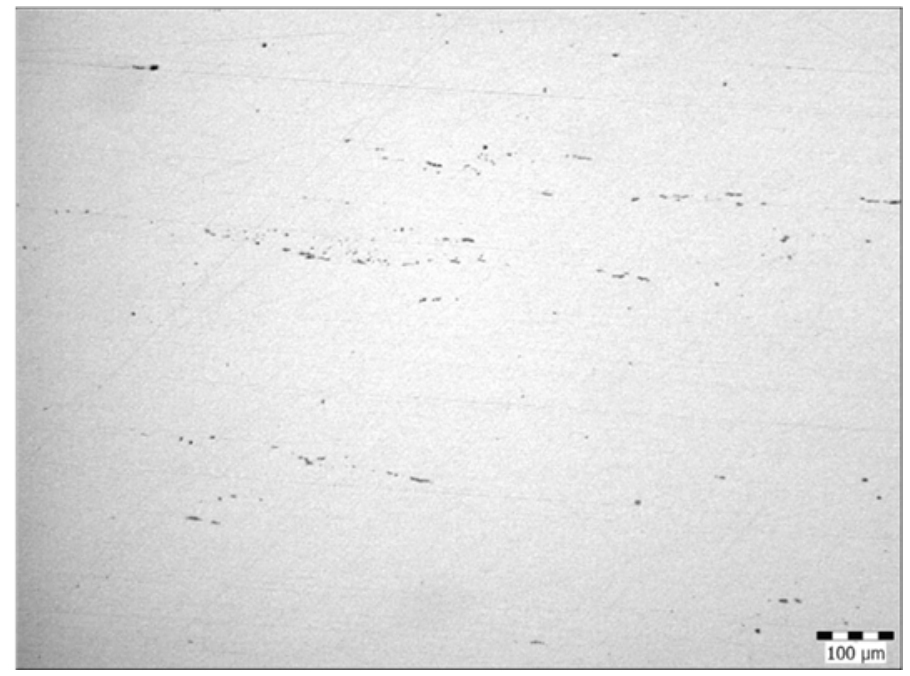

Figure 8. An example of sulfides in the $\mathrm{CMnCr}$ steel with 0.08 wt. \% of $\mathrm{Bi}$.

Electron microscopic analysis of $\mathrm{Bi}$-free $\mathrm{CMnCr}$ steel revealed numerous clusters of both elongated gray particles and various dark particles. Using X-ray microanalysis, their chemical composition was identified as manganese sulfides and aluminum oxides. The characteristic Energy dispersive X-ray spectra (EDX) of these particles are shown in Figure 9, and their composition in Table 3.

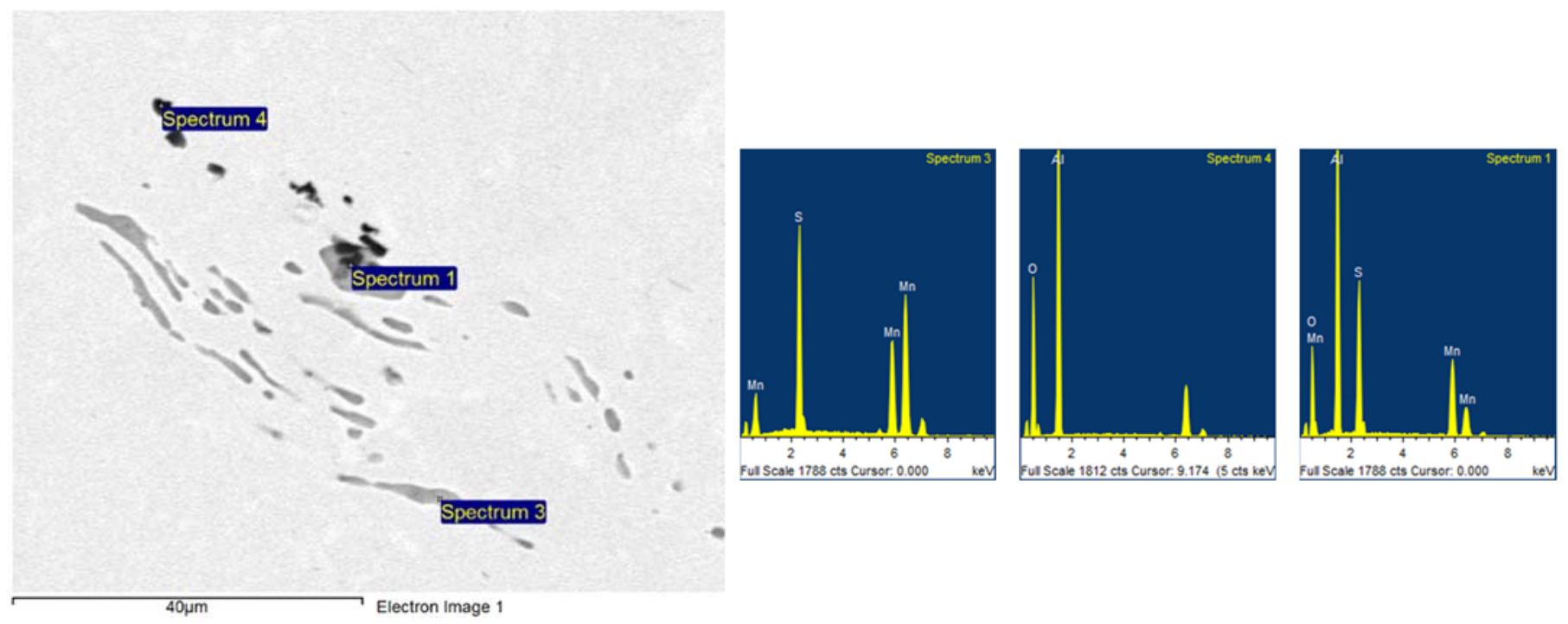

Figure 9. EDX spectra of individual particles in Bi-free $\mathrm{CMnCr}$ steel.

Table 3. Chemical composition of particles in Bi-free CMnCr steel [wt. \%].

\begin{tabular}{ccccc}
\hline Elements & O & Al & S & Mn \\
\hline spectrum 1 & - & 3.7 & 35.8 & 60.5 \\
\hline spectrum 3 & - & - & 40.0 & 60.0 \\
\hline spectrum 4 & 57.5 & 42.5 & - & - \\
\hline
\end{tabular}

In addition to $\mathrm{MnS}$ and $\mathrm{Al}_{2} \mathrm{O}_{3}$, light bismuth particles were detected in $\mathrm{CMnCr}$ steel with 0.08 wt. \% Bi. The EDX spectra characteristic of individual particles are shown in Figure 10, and their chemical composition is stated in Table 4. 


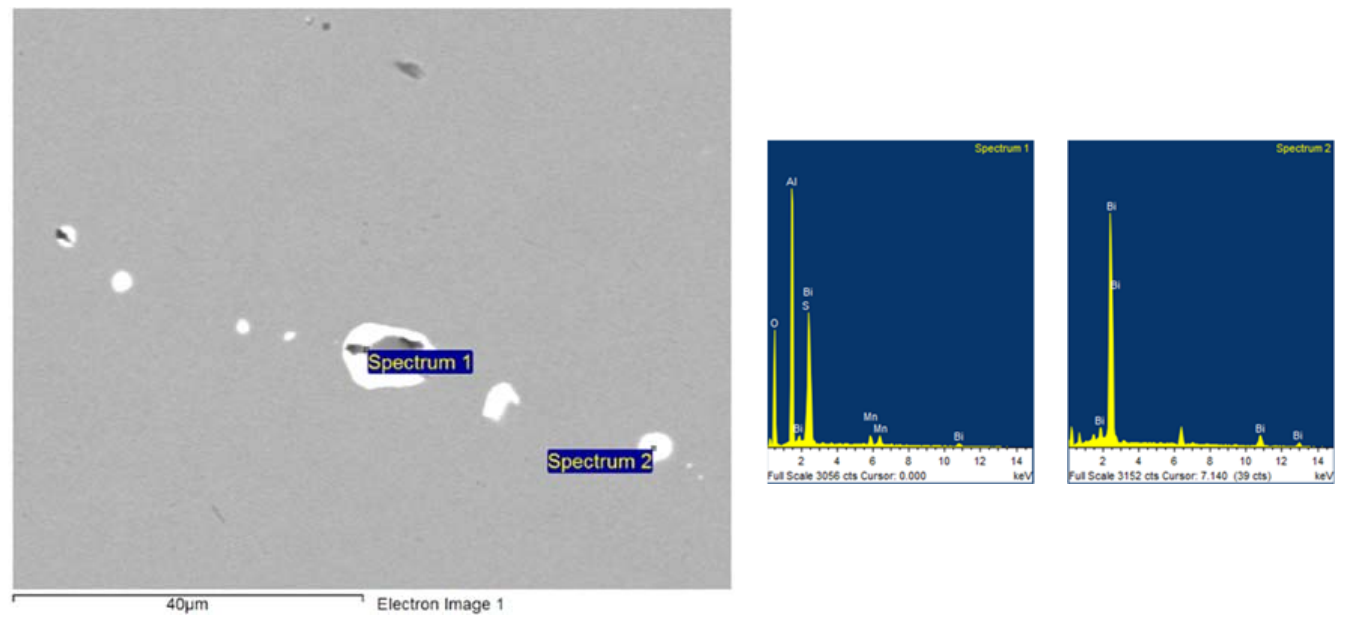

Figure 10. EDX spectra of individual particles in $\mathrm{CMnCr}$ steel with $0.08 \% \mathrm{Bi}$.

Table 4. Chemical composition [in wt. \%] of individual areas in inclusions, CMnCr steel with 0.08 wt. \% Bi [wt. \%]

\begin{tabular}{cccccc}
\hline Elements & O & Al & S & Mn & Bi \\
\hline spectrum 1 & 37.6 & 20.0 & 1.8 & 2.3 & 38.3 \\
\hline spectrum 2 & - & - & - & - & 100 \\
\hline
\end{tabular}

For the area distribution of the individual elements in the inclusions Energy Dispersive Spectroscopy (EDS) mapping when each element has a different color, see Figure 11.

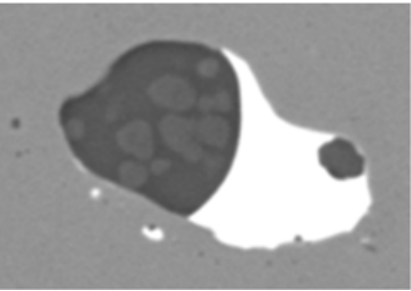

(a) Particle image

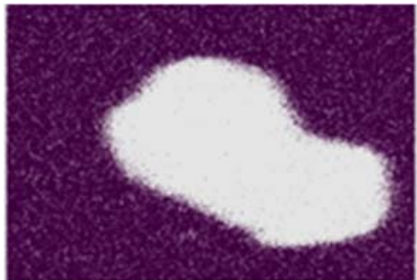

(b) Iron

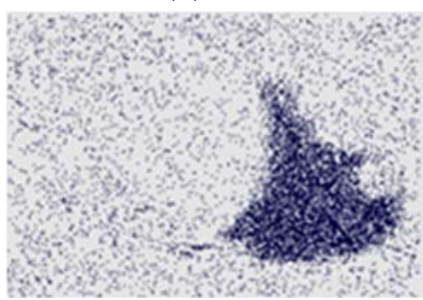

(e) Bismuth

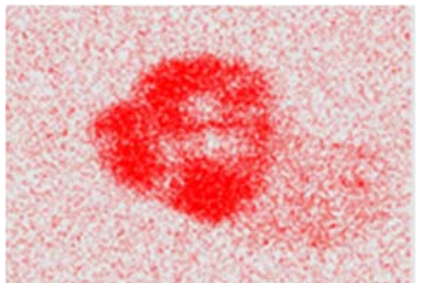

(c) Silicon

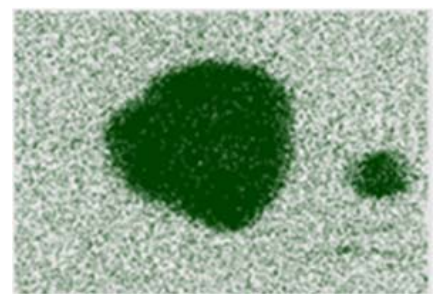

(f) Manganese

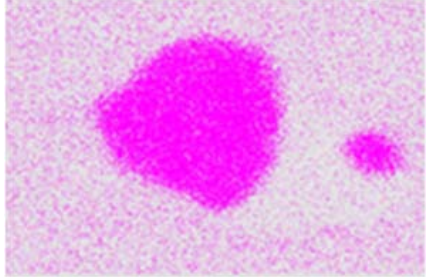

(d) Oxygen

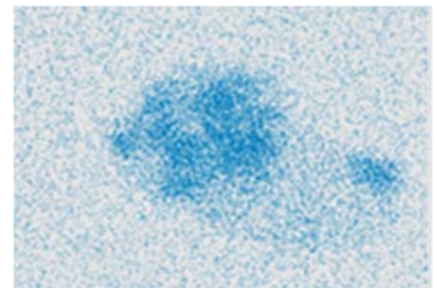

(g) Aluminium

Figure 11. EDS mapping-distribution of individual elements (b) Iron, (c) Silicon, (d) Oxygen, (e) Bismuth, (f) Manganese, (g) Aluminiumin a (a) complex particle with Bi in CMnCr steel with 0.08 wt. $\% \mathrm{Bi}$ 
CMnCr steel with $0.12 \%$ Bi contained Bi particles, which were precipitated on manganese sulfides, or on complex particles consisting of manganese sulfide and aluminum oxide. The small individual Bi particles were predominantly globular, and the coarser particles were usually elongated. Typical EDX phase spectra are shown in Figure 12, the chemical compositions in Table 5, and the mapping results in Figure 13.

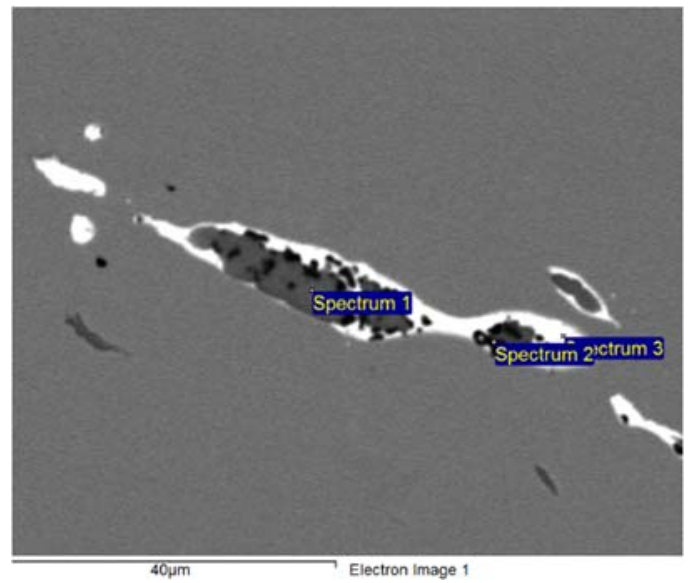

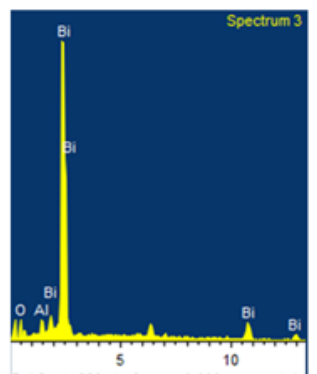

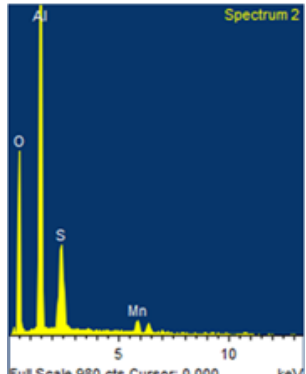

Ful Scale 990 cts Cursor 0000

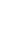

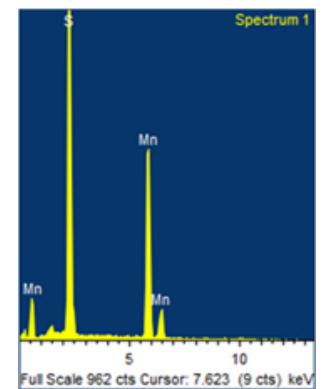

Eul Scale 962 cts Cursor. 7.623 ( 9 cts) keV

Figure 12. EDX spectra of complex particles in CMnCr steel with $0.12 \mathrm{wt}$. \% Bi.

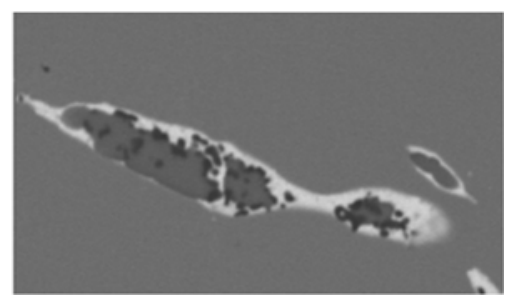

(a) Particle image

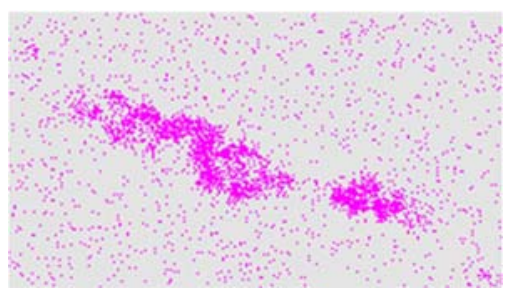

(b) Aluminium

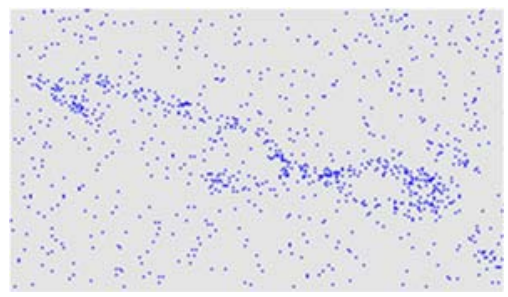

(e) Bismuth

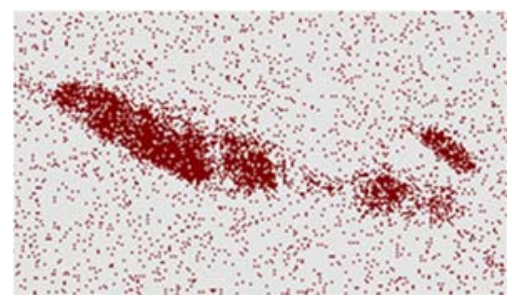

(c) Sulphur

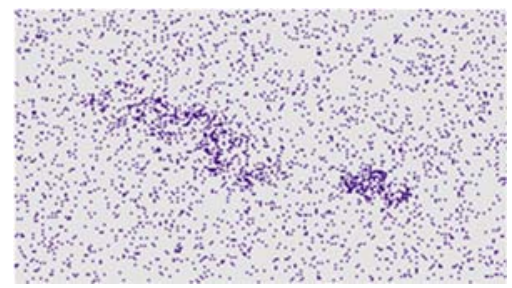

(f) Oxygen

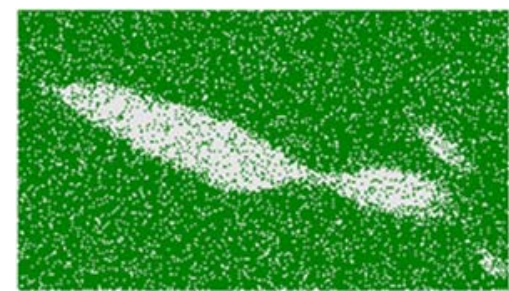

(d) Iron

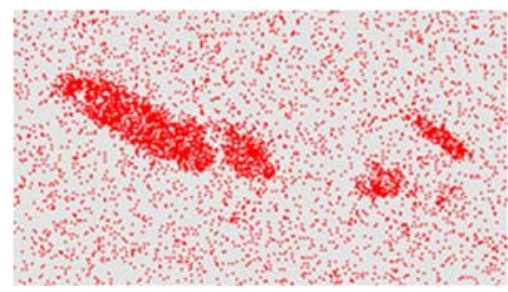

(g) Manganese

Figure 13. EDS mapping — distribution of individual elements (b) Aluminium, (c) Sulphur, (d) Iron, (e) Bismuth, (f) Oxygen, (g) Manganese in a (a) complex particle with Bi, in CMnCr steel with 0.12 wt. \% Bi. 
Table 5. Local chemical composition [in wt. \%] of individual parts of non-metallic inclusions, steel with 0.12 wt. \% Bi [wt. \%]

\begin{tabular}{cccccc}
\hline Elements & O & Al & S & Mn & Bi \\
\hline spectrum 1 & - & - & 40.3 & 59.7 & - \\
\hline spectrum 2 & 50.2 & 45.7 & 0.2 & 3.9 & - \\
\hline spectrum 3 & 9.9 & 1.3 & - & - & 88.8 \\
\hline
\end{tabular}

Non-metallic particles were formed in all evaluated samples, identified as manganese sulfides, aluminum oxides, or oxysulfides. These inclusions were found both singly and in clusters. In steel with $0.12 \mathrm{wt}$. \% $\mathrm{Bi}$ and steel with $0.08 \mathrm{wt}$. \% $\mathrm{Bi}$, very different and strikingly bright particles were contrasted, and their chemical composition corresponded to bismuth. These particles formed separately in the form of globules, but also as envelopes of elongated $\mathrm{MnS}$ or $\mathrm{Al}_{2} \mathrm{O}_{3}$ particles precipitated in rows. The frequency of $\mathrm{Bi}$ particles was highest for steel with $0.12 \% \mathrm{Bi}$.

The microstructure of all tested steels was very similar, and was composed of ferrite and pearlite with islands of bainite. Towards the center of the bars, variable shapes and sizes of bainite blocks were observed. The microstructure of $\mathrm{CMnCr}$ steel with $0.08 \mathrm{wt}$. \% Bi from the subsurface and axial area of the bar is illustrated on Figures 14 and 15.

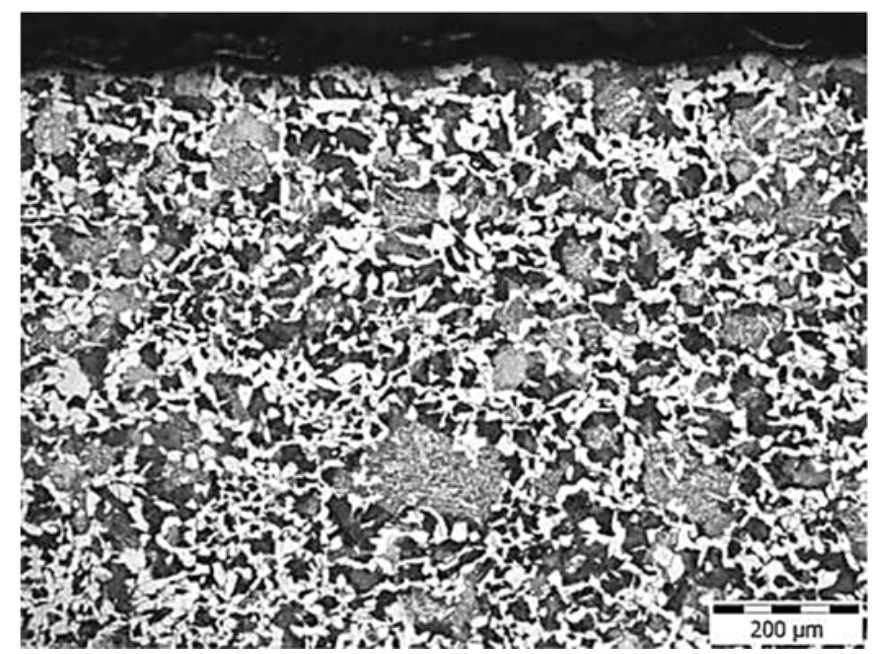

Figure 14. Microstructure in the subsurface area of $\mathrm{CMnCr}$ steel with $0.08 \mathrm{wt}$ \% $\mathrm{Bi}$.

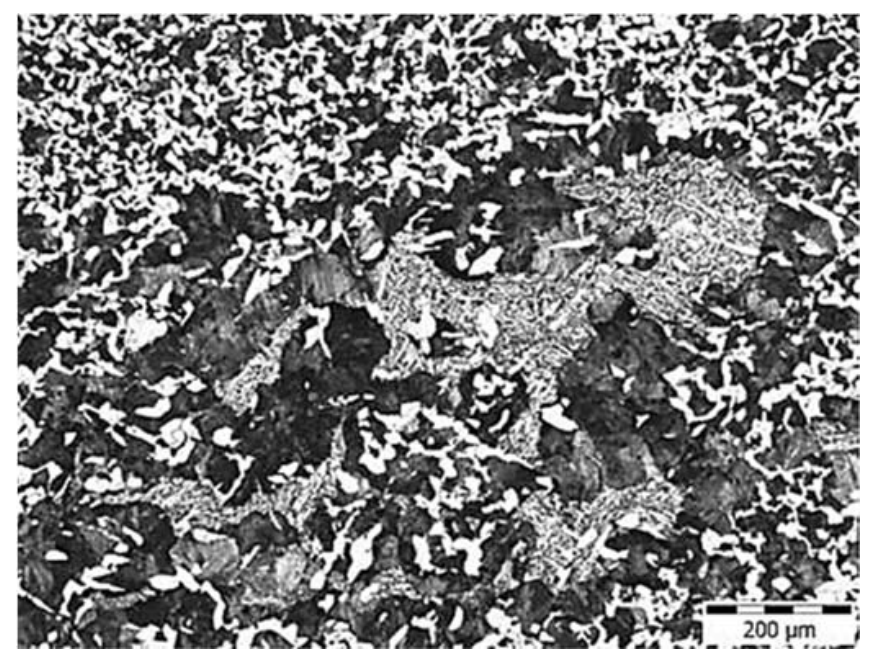

Figure 15. Microstructure in the axial area of $\mathrm{CMnCr}$ steel with 0.08 wt. \% Bi. 


\section{Conclusions}

This article compares the technological and material properties of $\mathrm{CMnCr}$ steels with 0 wt. $\% \mathrm{Bi}, 0.08$ wt. $\% \mathrm{Bi}$ and 0.12 wt. \% Bi.

The most important conclusions can be summarized as follows:

- For producing small heats in atmospheric-induction melting furnaces, it is best to cast the steel melt into a ladle and alloy it there using bismuth in the form of a filled profile with a composition of 93 wt. \% $\mathrm{Bi}$ and 7 wt. $\% \mathrm{CaCO}_{3}$.

- The Bi alloying efficiency was around $20 \%$.

- Using plastometric tests, the range of forming temperatures was set at $1160-1050{ }^{\circ} \mathrm{C}$, and the most suitable strain rate was $1.94 \mathrm{~s}^{-1}$.

- With increasing Bi content, the formability of the steels decreased in both the torsion tests and the forgings.

- Manganese sulfides, aluminum oxides, or oxysulfides, which were segregated both individually and in clusters, were found in the matrix of all tested steels. In steels with $\mathrm{Bi}$, the Bi particles were segregated both separately in the form of globules, but also as envelopes of elongated $\mathrm{MnS}$ or $\mathrm{Al}_{2} \mathrm{O}_{3}$ particles segregated in rows.

- Distribution of sulfur inclusions evaluated by Baumann print showed that the occurrence of sulfur segregations in the steel with $0.12 \mathrm{wt}$. \% of $\mathrm{Bi}$ and the steel without Bi was essentially uniform over the whole area; these were dot-shaped sulfur segregations. For the steel with $0.08 \mathrm{wt}$. \% of $\mathrm{Bi}$, both dot-like and ray-ordered sulfur segregations were observed.

- Microstructure of steels was very similar ferritic-pearlitic, with islands of bainite. Towards the center of the bars, variable shapes and sizes of bainite blocks were observed.

- Machinability tests showed that in terms of the least tool wear, chip formation and shape, and heat dissipation, $\mathrm{CrMnCr}$ steel alloyed with $0.08 \mathrm{wt}$. \% Bi was the most satisfactory.

- In further research activities, it would be appropriate to verify the effect of slightly lower content than $0.08 \mathrm{wt}$. \% of $\mathrm{Bi}$ on the properties of the $\mathrm{CMnCr}$ steel.

Author Contributions: Conceptualization, V.K. and P.J.; methodology, V.K., Z.K., L.K., P.J. and O.K.; Validation, P.J.; formal analysis, V.K. and P.J. All authors have read and agreed to the published version of the manuscript.

Funding: This work was supported by the EU Regional Development Fund within the Operational Programme Research, Development and Education under the aegis of Ministry of Education, Youth and Sports of the Czech Republic; Project number CZ.02.1.01/0.0/0.0/17_049/0008426.

Institutional Review Board Statement: Not applicable.

Informed Consent Statement: Not applicable.

Data Availability Statement: Not applicable.

Conflicts of Interest: The authors declare no conflict of interest.

\section{References}

1. Luiz, N.E.; Machado, A.R. Development trends and review of free-machining steels, Proceedings of the Institution of Mechanical Engineers. J. Eng. Manuf. 2008, 222, 347-360. [CrossRef]

2. Essel, I. Machinability Enhancement of Non-Leaded Free Cutting Steels. Ph.D. Thesis, Rheinisch-Westfälischen Technischen Hochschule Aachen, Aachen, Germany, 2006.

3. Živković, D.; Štrbac, N.; Ekinović, S.; Begović, E. Lead-Free Free-Cutting Steels as Modern Environmentally Friendly Materials. ResearchGate. 2011. Available online: https://www.researchgate.net/publication/281812810 (accessed on 8 September 2021).

4. $\quad$ Roper, C.R., Jr.; Strattan, J.K.; Hetherington, R., Jr.; Hiller, A.J.; Lukens Inc. Process for Making Resulfurized Machinable Steel. U.S. Patent 4,373,967, 15 February 1983.

5. Thivellier, D.; Seraphin, L.; Tricot, R. Free Machining Steel. U.S. Patent 4,004,922, 25 January 1977.

6. Samuels, L.E. Optical Microscopy of Carbon Steels; ASM International: Almere, The Netherlands, 1980; 594p, ISBN 978-0871700827. 
7. Ray, K.K.; Das, J.; Dixit, A.; Chakraborty, M.; Chakravorty, S.; Guha, S.N. Effect of cold deformation on the machinability of a free cutting steel. Mater. Manuf. Process. 2006, 21, 333-340. [CrossRef]

8. Sridhar, G. Failure Analysis of Free-Cutting Grade Steels: A Case Study. PROCEEDINGS: COFA-1997CNML JAMSHEDPUR pp. 121-139. Available online: https://core.ac.uk/download/pdf/297711126.pdf (accessed on 17 September 2021).

9. Ånmark, N.; Karasev, A.; Jönsson, P.G. The effect of different non-metallic inclusions on the machinability of steels. Materials 2015, 8, 751-783. [CrossRef] [PubMed]

10. Nazabal, J.L.; Urcola, J.J.; Fuentes, M. Hot Ductility of Leaded Free-Cutting Steels. Metallography 1984, 17, 439-453. [CrossRef]

11. Hu, S.; Li, Z.; Fan, T.; Fu, J. Effect of Bismuth on Sulfide in High Sulfur Free-cutting Steel. Mater. Sci. Eng. 2019, 611, 012017. [CrossRef]

12. Desaigues, C.; Lescalier, A.; Bomont, O. High Strength Steel solutions for automotive parts: State of the art of machinability enhancement and further developments. In Proceedings of the Tenth International Conference on High Speed Machining, Darmstadt, Germany, 26-27 September 2013; TU Darmstadt: Darmstadt, Germany, 2013; pp. 270-277.

13. Kato, S.; Yamaguchi, K.; Yamada, M. Stress Distribution at the Interface Betweeen Tool and Chip in Machining. J. Eng. Ind. 1972, 94, 683-689. [CrossRef]

14. Pickering, F.B.; Gladman, T. A Modern Approach to Ferrous Metallography. Steel Coal 1962, 1178-1187.

15. Pielet, H.M.; Frank, L.A.; Edgar, W.; Alavanja, M. Steel Product with Globular Manganese Sulfide Inclusions. U.S. Patent 4,881,990, 21 November 1989.

16. Garcia, C.I.; Hua, M.; Miller, M.K.; Deardo, A.J. Application of Grain Boundary Engineering in Lead-free “Green Steel”. ISIJ Int. 2003, 43, 2023-2027. [CrossRef]

17. Arendt, C. Angepasste Stähle zur Effektiven und Umweltgerechten Drehbearbeitung. Ph.D. Thesis, Leigniz Universität Hannover, Hannover, Germany, 2004.

18. Ryabov, A.V.; Dyakonov, A.A.; Vakhitov, M.G. A new free-machining steel containing bismuth and calcium. Mater. Sci. Forum 2016, 857, 251-255. [CrossRef]

19. Chaus, S.H. Application of Bismuth for Solidification Structure Refinement and Properties Enhancement in As-cast High-speed Steels. ISIJ Int. 2005, 45, 1297-1306. [CrossRef]

20. Nordberg, G.F.; Fowler, B.A.; Nordberg, M.; Frieberg, L. Handbook on the Toxicology of Metals, 3rd ed.; Academic Press, Inc.: Cambridge, MA, USA, 2007; pp. 433-443.

21. Liu, H.T.; Chen, W.Q. Hot ductility of eco-friendly low carbon resulphurised free cutting steel with bismuth. Ironmak. Steelmak. 2014, 41, 19-25. [CrossRef]

22. Liu, H.; Yu, Y.; Chen, W.; Wang, Q.; Wang, G. Effect of Mn/S Ratio on the Hot Ductility of Eco-friendly Bi-S based Free Cutting Steel. High Temp. Mater. Proc. 2014, 33, 553-561. [CrossRef]

23. Koepfer, C. Anatomy of Free Machining Steel. Available online: https://www.productionmachining.com/articles/anatomy-offree-machining-steel (accessed on 24 September 2021).

24. Kim, M.S.; Lee, H.J.; Chang, Y.W. The Effect of Mn/S Ratio on Hot Ductility of Bi Bearing Free Cutting Steels. Key Eng. Mater. 2007, 345-346, 169-172. [CrossRef]

25. Onderka, B.; Jendrzejczyk-Handzlik, D.; Fitzner, K. Thermodynamic properties and phase equilibria in the ternary $\mathrm{Cu}-\mathrm{Pb}-\mathrm{Fe}$ system. Arch. Metal. Mater. 2013, 58, 542-548. [CrossRef]

26. Salazar, K.; Marcia, K.M. Metal Prices in the United States through 2010; U.S. Geological Survey: Reston, VA, USA, 2013 ; pp. 17-18. Available online: https:/ / pubs.usgs.gov/sir/2012/5188/sir2012-5188.pdf (accessed on 22 June 2021).

27. Peng, H.; Tang, Y.; Zhang, Y.; Wang, X.; Zhou, C. Effect of MnS and Its Size on the Heterogeneous Nucleation and Precipitation of Bismuth in Steel. Indian Inst. Met. 2019, 73, 4. [CrossRef] 